A survey of blind children in California provides basic information for planning programs of prevention.

\title{
Blindness in California Children
}

\author{
NEDRA B. BELLOC, M.A., PHYLliS H. MATTSON, M.S., and \\ WILLIAM D. SIMMONS, M.P.H.
}

M

AJOR causes of blindness in each age group must be fully explored before preventive effort' 'can be productive. Planning special educational services for blind children requires a knowledge of the numbers of such children in the population.

In 1954, a prevention of blindness project was undertaken by the California State Department of Public Health. The need to determine the causes of blindness in children and to obtain information on their number and age distribution resulted in this study, done in 1956.

Previous surveys of blind children made by the National Society for the Prevention of Blindness $(1,2)$ have been limited necessarily to reports from a few cooperating agencies in each participating State. In an effort to make this survey as comprehensive as possible, the prevention of blindness project undertook to gather data about all of the blind and partially sighted children known to school districts with special classes, the State school for the blind, the Variety Club's Blind Babies' Foundation,

The authors, at the time of the survey, were associated with the prevention of blindness project, a special assignment in the division of preventive medical services, California State Department of Public Health in Berkeley. Mrs. Belloc and Mrs. Mattson were respectively associate statistician and junior public health analyst. Mr. Simmons was supervisor. The project was financed by a grant from the $W . K$. Kellogg Foundation. and the California State Department of Education.

The staff of the project visited each of the 29 school districts with special classes, transcribing from the medical records data on visual acuity, pathology, etiology, other handicapping conditions, and prognosis, as well as age and sex of each child. Teachers and coordinators were asked whether they knew of other blind children who were not enrolled in the special classes. Such children were included if medical records were available which enabled an assessment of their difficulty either in terms of visual acuity or diagnosis. The Blind Babies' Foundation, a voluntary agency which provides a home counseling and teaching service, supplied similar information for children currently on its rolls. The department of education made available its file on children about whom teachers or parents had inquired. These records were used only if there had been communication about the child during 1955 or 1956 (the 15 months preceding the survey), and suffcient information had been given to establish either or both the visual acuity and diagnosis. Records duplicated from more than one source were eliminated.

Although information was gathered on more than 600 partially sighted children, this report is limited to blind children (those with visual acuity of $20 / 200$ or less in the better eye with maximum correction): Similarly, while records were obtained on a few children over 18 years of age, this report deals only with those 
under 18. Included were 1,338 children, of whom 568 were under the age of 6 , and 770 between 6 and 17.

\section{Coverage}

These children do not represent a complete count of the blind children in the State. At least two sources of children known to be blind were not included. A private nursery for blind children in southern California reported that it had 18 children enrolled, and 52 others on its "cradle roll," but refused to permit its medical records to be used for the study. Consideration was given to the inclusion of children in Sonoma, Porterville, and Pacific State Hospitals, and estimates received from the superintendents of these institutions indicate that there are approximately 160 blind children in residence. These were not included partly because it was felt that the primary handicap was not blindness, and also it would have been difficult to obtain complete diagnostic information on a case-by-case basis.

That there may be as many as 200 blind children in the State who are not enrolled in school or known to agencies offering services to preschool blind children was suggested by a review of the records in the department of education. In addition to the 110 children about whom there had been correspondence in 1955 or 1956 , there were 229 last discussed in correspondence dated 1954 or earlier. It is difficult to believe that many of these children have died or moved from California. There was evidence that cerebral palsy or mental retardation was present in a fairly high proportion of these cases, and it is possible that some are receiving care in institutions for these conditions. It seems likely that a substantial number of blind children are being cared for at home or in regular schools, without benefit of the specialized training required if they are to become self-sufficient adults.

Even with the exclusions mentioned above, the number of children included in the survey yields rates of blindness considerably higher than those found by previous studies $(1, \mathscr{2})$. Because of the method used, these rates may be considered to represent minimum estimates of the number of blind children in California.
At least 33 children in every 100,000 were blind, with the rate among preschool children as high as 46 in those 4 years of age (table 1).

The high rates among children 2,3 , and 4 years of age were due to the prevalence of retrolental fibroplasia in that age group. Fortunately, it was discovered that this condition was caused by the use of excessive oxygen for newborn premature infants (3). The establishment of control measures for the administration of oxygen (4) has reduced drastically the incidence of this condition in the 3 years since this survey was made. Recent checks with the two agencies in California concerned with preschool blind children (5) revealed that they were serving 23 children with retrolental fibroplasia who were born in 1955, 9 born in 1956, 1 born in 1957, and so far none born in 1958. It is to be noted that children with retrolental fibroplasia born in the peak years 195153 are now reaching school age. Unless their increased number is offset by decreases in blind-

Table 1. Number of blind children covered in survey, with rates per 100,000 children, by age, California, 1956

\begin{tabular}{|c|c|c|}
\hline Age, in years 1 & $\begin{array}{c}\text { Total } \\
\text { number } \\
\text { in survey }\end{array}$ & $\begin{array}{c}\text { Rate per } \\
100,000 \\
\text { children }^{2}\end{array}$ \\
\hline Total $\ldots \ldots \ldots$ & 1, 338 & 33 \\
\hline 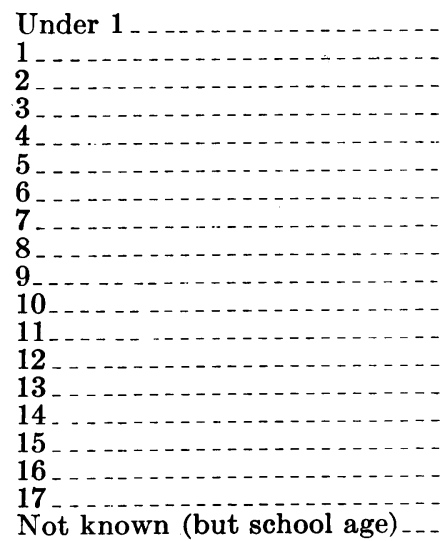 & $\begin{array}{r}28 \\
76 \\
132 \\
125 \\
126 \\
81 \\
105 \\
97 \\
85 \\
75 \\
74 \\
67 \\
66 \\
48 \\
43 \\
38 \\
37 \\
28 \\
7\end{array}$ & $\begin{array}{rr}(3) & \\
(3) & 43 \\
& 43 \\
46 \\
30 \\
38 \\
35 \\
30 \\
30 \\
35 \\
32 \\
32 \\
25 \\
26 \\
24 \\
24 \\
18 \\
----\end{array}$ \\
\hline
\end{tabular}

1 As of Dec. 31, 1955.

2 Based on population estimates of the California State Department of Finance.

3 Rate not computed because coverage of very young children is obviously less complete than for other ages.

4 Coverage of 17-year-olds is probably less complete than for younger school-age children because many at this age have left school. 
Table 2. School status of 1,338 blind children, California, 1956

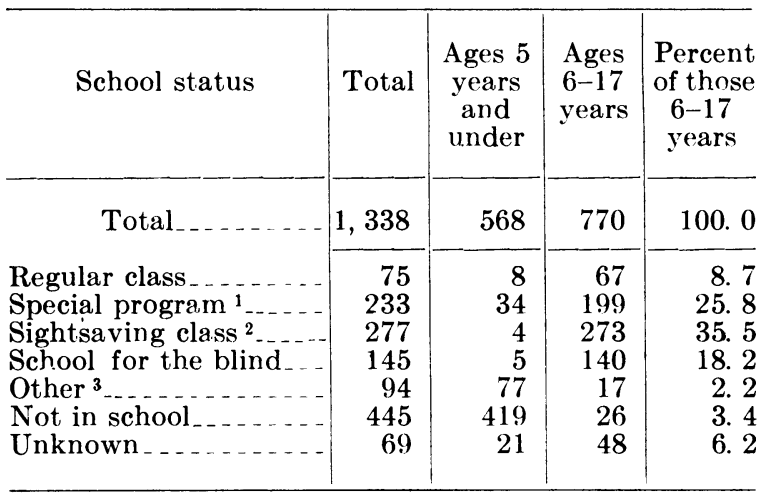

1 Regular classes with supplementary work in Braille. 2 Special classes using large-print textbooks.

${ }^{3}$ Includes nursery schools, tutors, and so forth.

ness due to other causes in the younger ages, we can expect during the next 10 or 12 years, as they move through the school grades, to deal with problems of education for a greatly increased number of blind children.

It is not surprising that most of the children were of school age and attending classes, since the records used in the study were obtained primarily from schools (table 2 ). The largest group of children ( 35 percent) were enrolled in so-called sightsaving classes, in which largeprint materials are used. Another 25 percent were enrolled in regular classes with work in Braille given by a special teacher. Eighteen

Table 3. Other handicapping conditions in 1,338 blind children, California, 1956

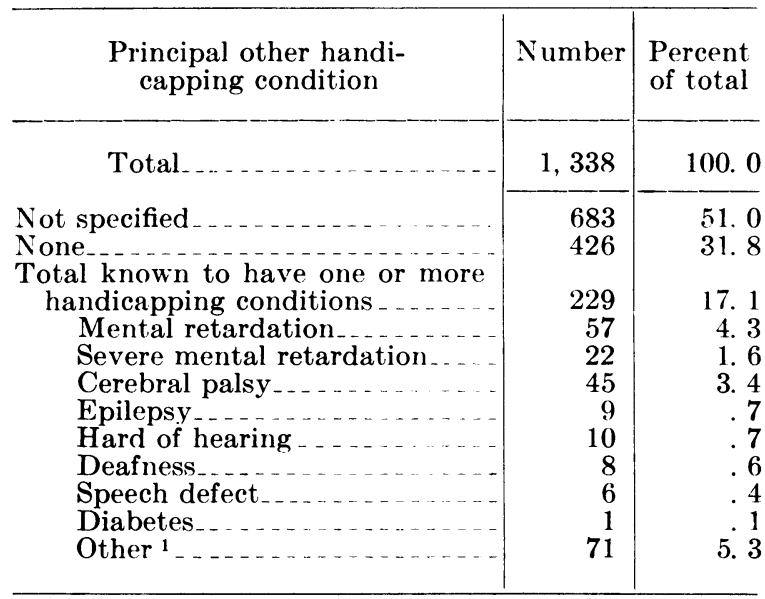

1 Includes congenital heart conditions, cleft palate, loss or malformation of arm or leg, developmental retardation, and emotional disturbances. percent attended the resident school for blind children in Berkeley.

Diagnostic information was taken from forms which differed in the various agencies. Many of them did not provide specifically for a description of other handicapping conditions. More than one-half of the records had no information about such conditions. It is therefore probable that the figures shown in table 3 represent an understatement of the number of these conditions present in conjunction with visual impairment. Severe conditions, however, such as mental retardation or cerebral palsy, would be likely to be mentioned if present, and were indicated in almost 10 percent of the records. Seventeen percent of all the children surveyed were known to have one or more handicapping conditions other than blindness.

\section{Causes of Blindness}

The diagnostic information given on the medical records was coded according to the Standard Classification of Causes of Blindness recommended by the Committee on Statistics of the Blind, 1956 revision. Since many records showed multiple pathologies, it was necessary to adopt certain arbitrary rules for selecting the one to be coded. Congenital malformations were given preference over infectious conditions, and these in turn were coded before refractive errors or muscular difficulties. Optic nerve atrophy was not coded unless it appeared to be primary. Retrolental fibroplasia was coded as primary regardless of associated or complicating conditions. Nystagmus was coded only if it appeared alone. The etiology was coded with an abbreviation of the standard classification, since the number of cases did not warrant a finer breakdown.

The sites and types of affections of eye conditions are shown in table 4. Since retrolental fibroplasia caused a large proportion of blindness in the younger ages, this table divides the children into groups 5 years of age and younger and 6 to 17 years of age. Nearly threefourths of the former group were affected by retrolental fibroplasia. Structural anomalies accounted for more than one-quarter of the conditions in the older age group. Retinal 
Table 4. Site and type of affection of eye conditions of 1,338 blind children, California, 1956

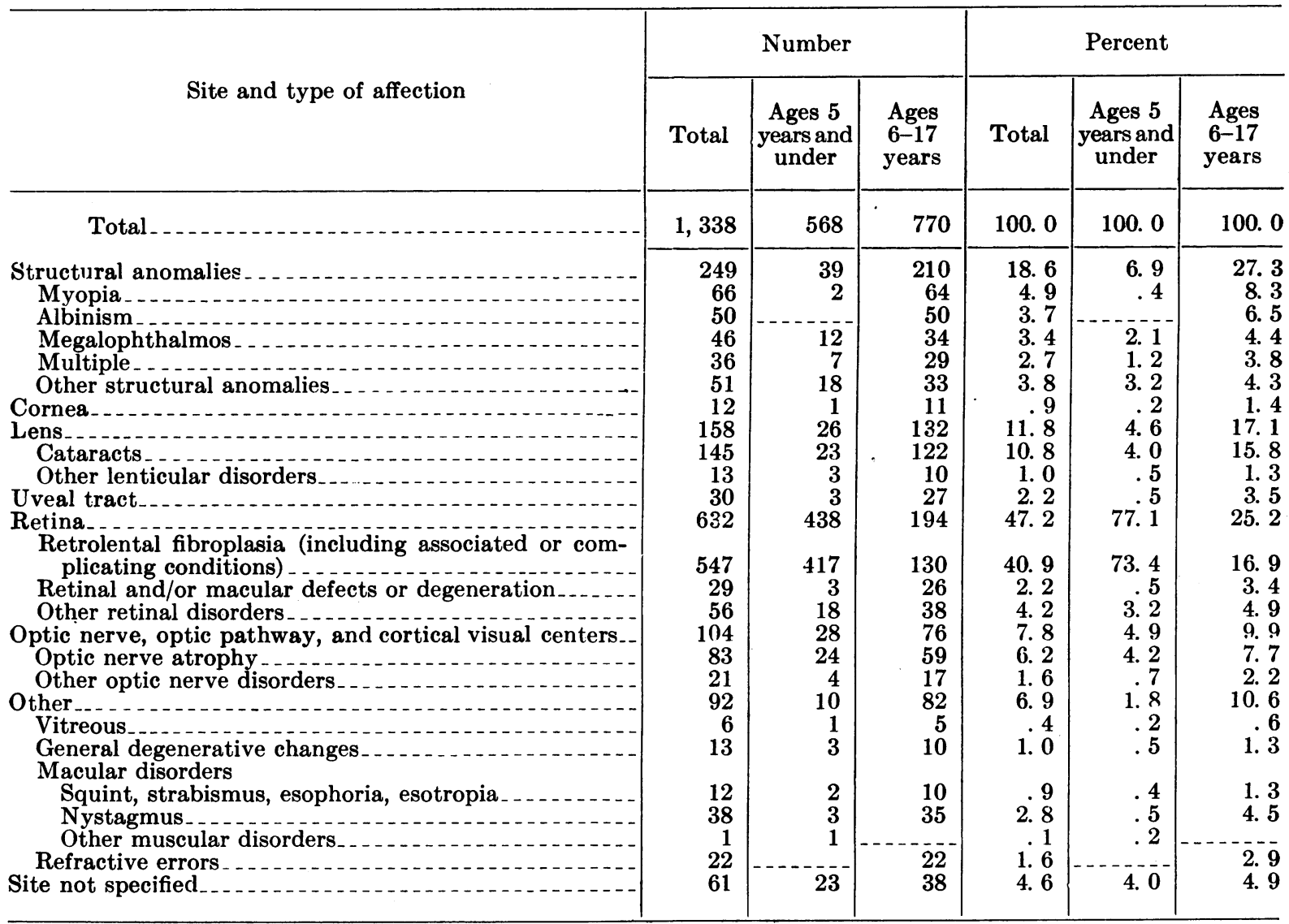

conditions, including retrolental fibroplasia, represented another 25 percent, and affections of the lens, primarily cataracts, totaled 17 percent.

Of more importance from the standpoint of preventive efforts are the causes of blindness shown in table 5. Administration of excessive oxygen was assumed to be the cause of retrolental fibroplasia in 547 children, or 41 percent of the total in all ages. Congenital conditions made up the next largest group, accounting for 14 percent of the preschool group and nearly half of those in the older age group. The etiology was unknown or unspecified in about 15 percent of the cases. It can be safely assumed that many of those for whom no etiology was given had conditions present at birth. If the number of blind children is to be substantially reduced, some way must be found to prevent occurrence of the conditions producing abnormalities in the newborn.

In most of the cases in this study, excluding retrolental fibroplasia, the actual cause of the blindness was unknown. It was merely reported as present at birth. This is an area in which careful, definitive research in the causes of blindness should be undertaken. Infections of the mother in pregnancy were said to be responsible for a little more than 2 percent of the cases, while infections of the child accounted for 1 percent.

Injuries, other than birth injuries, were responsible for blindness in 28 children, or 2.1 percent of the total. Since these were presumably all preventable, they warrant attention out of proportion to the small number of cases. In nearly 40 percent of the accident cases, the agent was not specified. Of those in which this detail was given, 7 cases, or nearly 30 percent, were due to explosions. Of these, four were boys between the ages of 6 and 10 who were playing with dynamite caps. Falls, including being dropped in infancy, were responsible for 6 cases. 
Table 5. Causes of blindness in 1,338 blind children, California, 1956

\begin{tabular}{|c|c|c|c|c|c|c|}
\hline \multirow[b]{2}{*}{ Cause of blindness } & \multicolumn{3}{|c|}{ Number } & \multicolumn{3}{|c|}{ Percent } \\
\hline & Total & $\begin{array}{l}\text { Ages } \\
5 \text { years } \\
\text { and } \\
\text { under }\end{array}$ & $\begin{array}{c}\text { Ages } \\
6-17 \\
\text { years }\end{array}$ & Total & $\begin{array}{l}\text { Ages } \\
5 \text { years } \\
\text { and } \\
\text { under }\end{array}$ & $\begin{array}{c}\text { Ages } \\
6-17 \\
\text { years }\end{array}$ \\
\hline Total & 1,338 & 568 & 770 & 100.0 & 100.0 & 100.0 \\
\hline $\begin{array}{l}\text { Prenatal infectious diseases } \\
\text { Postnatal infectious diseases } \\
\text { Birth injury } \\
\text { Other injury } \\
\text { Retrolental fibroplasia (excessive oxygen) } \\
\text { Neoplasms. } \\
\text { General diseases, not elsewhere classified } \\
\text { Congenital conditions, not elsewhere classified } \\
\text { Unknown or unspecified }\end{array}$ & $\begin{array}{r}30 \\
13 \\
11 \\
28 \\
547 \\
38 \\
12 \\
455 \\
204\end{array}$ & $\begin{array}{r}11 \\
2 \\
3 \\
3 \\
417 \\
15 \\
1 \\
79 \\
37\end{array}$ & $\begin{array}{r}19 \\
11 \\
8 \\
25 \\
130 \\
23 \\
11 \\
376 \\
167\end{array}$ & $\begin{array}{r}2.2 \\
1.0 \\
.8 \\
2.1 \\
40.9 \\
2.8 \\
.9 \\
34.0 \\
15.2\end{array}$ & $\begin{array}{r}1.9 \\
.4 \\
.5 \\
.5 \\
73.4 \\
2.6 \\
.2 \\
13.9 \\
6.5\end{array}$ & $\begin{array}{r}2.5 \\
1.4 \\
1.0 \\
3.2 \\
16.9 \\
3.0 \\
1.4 \\
48.8 \\
21.7\end{array}$ \\
\hline
\end{tabular}

Tables 4 and 5 were tabulated for the condition in the better eye, which is consistent with the basis upon which the criterion for determination of blindness rests. It was recognized that this may have caused the loss for comparative purposes of a few serious conditions such as neoplasms, in favor of the affection of the better eye which might have a loss of vision due to myopia. A review of the records revealed that there were only 27 cases in which the coding for the two eyes would have been different. The net effect of changes in coding for these 27 cases would have been negligible. Adding the two neoplasms, for example, would have raised the percentage attributed to this cause from 2.8 to 3.0 .

\section{Summary}

This study was undertaken to determine the causes of blindness among children in California and the number and age distribution of such children. Data were gathered from the medical records available in all school districts with special classes for blind and partially sighted children, the State school for the blind, the State department of education, and the Variety Club's Blind Babies' Foundation. While the coverage is not complete, it is believed that a very high proportion of the total number of blind children in the State is included.

The rate of blindness among children under the age of 18 was found to be 33 per 100,000 with the rate among preschool children as high as 46 in those 4 years of age. The high rate in the latter group is due to the large number of children born in the years 1951-53 who were blinded by retrolental fibroplasia, a condition found to be due to the administration of excessive oxygen to newborns.

Congenital conditions, primarily of unknown origin, were found to be the cause of a large proportion of blindness in the two age groups studied. A substantial reduction in the number of blind children in future years can only be achieved through the determination of ways to prevent these conditions.

Accidents, which are responsible for a relatively small number of cases, are nonetheless important since it may be possible by the regulation of such hazards as dynamite caps to prevent some tragic cases of blindness in young children.

\section{REFERENCES}

(1) Kerby, C. E.: Blindness in preschool children. Sight-Saving Rev. 24: 15-29, Spring 1954.

(2) Kerby, C. E.: Causes of blindness in children of school age. Sight-Saving Rev. 28: 10-21. Spring 1958.

(3) Kinsey, V. E., Jacobus, J. T., and Hemphili, F. M. : Cooperative study of retrolental fibroplasia and the use of oxygen. A.M.A. Arch. Ophth. 56: 481-543, October 1956.

(4) California State Department of Public Health: Message to physicians on oxygen administration and retrolental fibroplasiá. June 1955.

(5) California State Department of Public Health : Report on retrolental fibroplasia. Family Health Bull. 1: 2, September 1958. 